\author{
Genetics of Alzheimer's Disease \\ Some molecular understanding of a diverse phenotype \\ DAVID ST CLAIR
}

Alzheimer's disease is the leading cause of dementia in the elderly (Schoenberg et al, 1987); it is also an important cause of dementia in those under the age of 65, so-called presenile dementia; an incidence in Scotland of 22 per 100000 in an at-risk population between the ages of 40 and 60 was recently reported for probable Alzheimer's disease, and 40 per 100000 for broad cases of Alzheimer's disease (McGonigal et al, 1993). It is a clinicopathological diagnosis and demands clinical evidence of a dementing process for a probable diagnosis, and neuropathological hallmarks of excessive amyloid plaques and neurofibrillary tangles for a definite diagnosis. At the same time, Alzheimer's disease needs to be differentiated from other forms of presenile and senile dementia, of which the multi-infarct type comprises the largest category. However, the traditional distinction between those two groups of dementias is not absolute. There is considerable clinical and neuropathological overlap between the disorders, even in the less common presenile cases where, if the two are separate entities, overlap ought to be rare (St Clair \& Whalley, 1983). (Evidence of genetic overlap is discussed later.)

\section{Clinical genetics}

Alzheimer's disease is a familial disorder. There is a threefold increased incidence of the disease in firstdegree relatives of probands compared with the base rate in the population. The finding is most pronounced in the relatives of people with presenile dementia, but is also observed with senile dementia (Van Duijn et al, 1993). It is also possible to identify rare pedigrees, usually with early onset of illness, in which the inheritance follows an intosomal dominant Mendelian pattern. No recessive, $\mathrm{X}$-linked or mitochondrial inheritance patterns have been observed.

Patients with Down's syndrome or trisomy chromosome 21 also have a very high risk of earlyonset Alzheimer's disease, and a few phenotypically normal people with Alzheimer's disease have mosaic trisomy 21 (Rowe et al, 1989).

Apart from these basic observations, little can be said about the clinical genetics of Alzheimer's disease. Most cases are either sporadic or apparently sporadic, and similar concordance rates are found in both monozygotic and dizygotic twin pairs (Nee et al, 1987). This suggests that in a high proportion of cases, genetic susceptibility may be a necessary but insufficient cause of the disease.

Segregation analysis of patterns of familial clustering may best be explained by transmission of autosomal dominant gene(s) with reduced penetrance, together with a multifactorial genetic and environmental background (Van Duijn et al, 1993).

\section{Molecular genetics}

Fortunately, the molecular biology and genetics of Alzheimer's disease are currently subject to an intensive and fast-moving research programme worldwide. The prospects of gaining insight into fundamental aspects of the disorder are now excellent. However, the sheer complexity of the emerging picture demands a sober view as to the speed with which this new knowledge can influence clinical practice.

\section{Presenile dementia}

The molecular genetics of Alzheimer's disease got underway in earnest with the identification of the gene for a fragment of the amyloid precursor protein (APP), called A4 peptide. This was found in the brain amyloid plaques and vascular deposits associated with the disease; it is not, however, a major constituent of neurofibrillary tangles, where tau protein predominates (Haines, 1991).

Subsequently, the APP gene was mapped to the region of chromosome 21 associated with Down's syndrome. Around the same time, genetic linkage studies in a few large families with early-onset autosomal dominant Alzheimer's disease mapped a putative locus to the same region of chromosome 21 (St George Hyslop et al, 1987).

Although the APP gene was initially considered a candidate, recombinants were found in linked pedigrees between the APP gene and Alzheimer's disease, and on this basis APP was apparently eliminated as a candidate. However, shortly afterwards a family with hereditary cerebral haemorrhage of the Dutch type was discovered to have mutations in the APP gene, in the A4 peptide coding region at codon 693 of the APP 770 transcript, near the site 
where the peptide is normally cleaved into a large soluble fragment and a smaller, membrane-bound peptide (Levy et al, 1990).

This persuaded Dr John Hardy and his colleagues while at St Mary's Hospital, London, to examine the gene for mutations in a subgroup of their families with autosomal dominant Alzheimer's disease linked to chromosome 21 (Goate et al, 1991). They found a Val $\rightarrow$ Ile substitution at codon 717 which cosegregated with illness in two pedigrees. Subsequently, other substitutions in the same codon associated with Alzheimer's disease, together with other mutations in the same region, have been reported.

Unfortunately, all these mutations are extremely rare, and even when combined account for a very small proportion of presenile dementia (Naruse et al, 1991; Murrell et al, 1991; Chartier-Harlin et al, 1991; Mullan et al, 1992b). Their discovery, however, has had two important theoretical consequences. Firstly, it has led to the hypothesis that the APP gene occupies a key role in an amyloid cascade that is fundamental to the molecular pathophysiology of Alzheimer's disease (Hardy, 1992). Secondly, the disease phenotypes associated with the various mutations, all close by each other in exons 16 and 17 , show remarkable diversity. Some patients present with classic Alzheimer's disease while others have recurrent strokes, even in the same family and with the same mutation. This raises basic questions as to the validity at the molecular level of separating Alzheimer's disease from other neuropsychiatric phenotypes.

Indeed, our own work suggests that these phenotypes may be unexpectedly diverse. We reported an Ala 713 Val substitution in a patient with chronic schizophrenia and subcortical cerebral ischaemia (Jones et al, 1992). The mutation produces a threeto sixfold increase in a $10 \mathrm{kd} \mathrm{C}$-terminal fragment of the APP gene. This may represent an increased stability once the fragment is trafficked to late endosomes and lysosomes, and so may be relatively more resistant to final proteolysis in the lysosome than the wild-type $10 \mathrm{kd}$ fragment (Selkoe et al, 1993). We hypothesise that this results in the pronounced whitematter ischaemia and schizophrenic symptoms found in the patient.

Unfortunately, neither mutation Ala 713 Val nor any other mutations of the APP gene have yet been found in several hundred schizophrenic patients examined to date. It does, however, emphasise that white-matter ischaemia, a recognised but minor feature of Alzheimer's disease, unrelated to congophilic angiopathy, can, if exaggerated, produce schizophrenic symptoms (Brun \& Englund, 1986).

The rarity of APP mutations in autosomal dominant Alzheimer's disease means that other gene loci must also be involved. Barely a year after the APP mutations were characterised, a new locus was found for early-onset Alzheimer's disease, in the middle of the long arm of chromosome 14. Four groups around the same time found linkage in about $70 \%$ of families with early-onset cases to the chromosome $14 \mathrm{q}$ region, just proximal to the serine protease inhibitor alpha I antichymotrypsin and distal to the protease Cathepsin G (Schellenberg $e t$ al, 1992; St George Hyslop et al, 1992; Van Broeckhoven et al, 1992; Mullan et al, 1992a).

Hints of linkage to this region had been found almost a decade earlier (Weitkamp et al, 1983), and interest was reawakened by the identification of alpha I antichymotrypsin at the core of the brain amyloid plaques of Alzheimer's disease (Abraham et al, 1988). However, neither of these genes are near enough to be the locus itself, whose identity remains to be determined. An international search for the gene is currently under way. Whether the gene when found supports the amyloid cascade hypothesis or causes Alzheimer's disease by a separate mechanism is a key question. For example, heat shock protein $\mathrm{HSPA}_{2}$ and c-fos oncogene, two candidate genes in the region, both respond to neuronal stress, which may be a factor in Alzheimer's disease (Abe et al, 1991; Royston et al, 1992). Each can bind to a consensus sequence in the promoter region of the APP gene and in theory cause overexpression. Mutations have not to date, however, been found in either gene.

It is likely, therefore, that mutations in the chromosome 14 locus will account for a high proportion of early-onset dominant Alzheimer's disease. However, a minority of pedigrees still do not map to either chromosome 21 or 14 . This suggests that a third locus exists. Whether these two latter loci will be implicated in the much more common familial and sporadic cases of presenile Alzheimer's disease, as opposed to autosomal dominant cases, remains to be seen. The tiny number of mutations found in the APP gene in familial and sporadic Alzheimer's disease is not encouraging. Other factors also need to be explained; for example, allele $\mathrm{HLA}-\mathrm{A}_{2}$, or a closely linked gene, confers susceptibility to earlyonset sporadic Alzheimer's disease in men (Payami et al, 1991).

\section{Senile Alzheimer's disease}

The most exciting new development is the recent observation by researchers at Duke University that the apolipoprotein E type 4 allele (Apo E E4) is genetically associated with the common late-onset familial and sporadic forms of Alzheimer's disease 
(Strittmater et al, 1993; Corder et al, 1993; Saunders et al, 1993). Several lines of evidence led them to examine apolipoprotein $\mathrm{E}$ in late-onset familial Alzheimer's disease (FAD). They observed several proteins in cerebrospinal fluid that bound immobilised amyloid $\beta$ peptide with high affinity. One of these was identified as Apo E (Strittmater et al, 1993) and was known to be localised to a region of chromosome 19 , which in previous studies had shown possible linkage to late-onset FAD (Pericak-Vance et al, 1991). Furthermore, antisera to Apo E stained senile plaques, neurofibrillary tangles, and cerebral vessel amyloid deposits in the brains of people who had suffered FAD (Wisnieski \& Frangione, 1992). On examination of DNA from 234 people from 42 FAD families, they found that almost all those in the study who had two copies of the Apo E E4 allele developed the disease, an eightfold increase in risk; they then went on to show that late-onset familial cases have the single E4 allele three times as often as in the general population, and late-onset sporadic cases twice as often (Saunders et al, 1993).

The results from Duke have now been confirmed by other groups. The implications of these findings are of immense interest. Apo E E4 allele is the first molecular genetic risk factor for common, senile Alzheimer's disease to be identified. It suggests, as long suspected, that multiple genes may contribute to increased susceptibility to senile Alzheimer's disease, but in contrast to mutations of the APP gene, they are not alone a sufficient cause.

Large-scale epidemiological studies are now being set up to examine E4 risk in various populations. The key molecular questions are also being investigated. Why do slightly different forms of this cholesterolcarrying protein dramatically change a person's vulnerability to Alzheimer's disease? Since the protein and $\beta$ amyloid bind to each other, will Apo E E4 support the amyloid cascade hypothesis? Not necessarily: Apo $\mathrm{E}$ also binds to the neurofibrillary tangles where the major protein is tau and not $\beta$ amyloid.

\section{Conclusions}

Dramatic inroads are being currently made into the molecular genetics of Alzheimer's disease, and they are likely to continue at an expanded pace in the years ahead. At last some of the clinical differences in presentation, rate of progress, and demographic characteristics of the disorder may be explainable at the molecular level. Progress is also likely in the development of animal models of the disease and novel methods of therapeutic intervention. However, the highly complex picture now emerging signals caution. It is important that the general public is not given an overoptimistic view of the prospects. It is likely to be many years before these exciting developments significantly reduce this major public health problem.

\section{References}

Abe, K., St George Hyslop, P. H., Tanzi, R. E., et al (1991) Induction of the amyloid precursor protein mRNA after heat shock in cultured human lymphoblastoid cells. Neuroscience Letters, 125, 169-171.

Abraham, C. R., Selkoe, D. J. \& Potter, H. (1988) Immunochemical identification of the serine protease inhibitor alpha I antichymotrypsin in the brain amploid deposits of Alzheimer's disease. Cell, 52, 487-501.

Brun, A. \& ENGLUND, D. E. (1986) A white matter disorder in dementia of the Alzheimer type: a pathoanatomical study. Annals of Neurology, 19, 253-262.

Chartier-Harlin, M. C., Crawford, F., Houlden, H., et al (1991) Early-onset Alzheimer's disease caused by mutations at codon 717 of the $\beta$-amyloid precursor protein gene. Nature, 353, 844-846.

Corder, E. H., Saunders, A. M., Strittmater, W. J., el al (1993) Gene dose of Apolipoprotein E type 4 allele and the risk of Alzheimer's disease in late onset families. Science, 261, 921-924.

Goate, A., Chartier-Harlin, M. C., Mullan, M., et al (1991) Segregation of a missense mutation in the amyloid precursor protein gene with familial Alzheimer's disease. Nature, 349, 704-706.

HAINES, J. L. (1991) The genetics of Alzheimer's disease. A teasing problem (editorial). American Journal of Human Genetics, 48, 1021-1025.

HARDY, J. A. (1992) An anatomical cascade hypothesis for Alzheimer's disease. Trends in Neuroscience, 15, 200-201.

Jones, C. T., Morris, S., YATES, C. M., et al (1992) Mutation in codon 713 of the $\beta$ amyloid precursor protein (APP) gene presenting with schizophrenia. Nature Genetics, 1, 306-309.

levy, E., Carman, M. D., Fernandez Madrid, J., el al (1990) Mutation of the Alzheimer's disease amyloid gene in hereditary cerebral haemorrhage, Dutch type. Science, 248, 1124-1125.

McGonigal, G., Thomas, B., McQuade, C., et al (1993) Epidemiology of Alzheimer's presenile dementia in Scotland, 1974-1988. British Medical Journal, 306, 680-683.

Mullan, M., Houlden, H., Windelspecth, M., et al (1992a) A locus for familial early-onset Alzheimer disease on the long arm of chromosome 14, proximal to the $\alpha 1$-antichymotrypsin gene. Nature Genetics, 2, 340-342.

-, Crawford, F., AXelman, K., et al (1992b) A pathogenic mutation for probable Alzheimer's disease in the amyloid precursor protein gene at the $\mathrm{N}$ terminus of $\beta$-amyloid. Nature Genetics, 1, 245-247.

MURRELL, J., FARLow, M., GHeTtI, B., et al (1991) A mutation in the amyloid precursor protein associated with hereditary Alzheimer disease. Science, 254, 97-99.

Naruse, S., Igarashi, S., Kobayashi, H., et al (1991) Missense mutation $\mathrm{Val} \rightarrow \mathrm{ll}$ in exon 17 of amyloid precursor protein gene in Japanese familial Alzheimer's disease. Lancet, $i$, 978979.

NeE, L. E., Eldridge, R., Sunderland, T., et al (1987) Dementia of the Alzheimer type: clinical and family study of 22 twin pairs. Neurology, 37, 359-363.

Payami, H., Kaye, J., Becker, W., et al (1991) hla-A2, or a closely linked gene, confers suceptibility to early-onset sporadic Alzheimer's disease in men. Neurology, 41, 1544-1548. 
Pericak-Vance, M. A., Bebout, J. L., Gaskell, P. C., et al (1991) Linkage studies in familial Alhzeimer disease: evidence for chromosome 19 linkage. American Journal of Human Genetics, 48, 1034-1050.

Rowe, F., Ridler, M. A. C. \& Gibberd, F. B. (1989) Presenile dementia associated with mosaic trisomy 21 in a patient with a Down's syndrome child. Lancet, $i, 229$.

Royston, M. L., Rothwel., N. \& Roberts, G. W. (1992) Alzheimer's disease from pathology to potential treatments. Trends in Pharmacological Sciences, 13, 131-133.

Saunders, A. M., Strittmatter, W. J., Schmechel, D., et al (1993) Association of Apolipoprotein E and Allele E4 with late onset familial and sporadic Alzheimer's disease. Neurology, 43, 1467-1472.

SChel.lenberG, G. D., Bird, T. D., Wijsman, E. M., et al (1992) Genetic linkage evidence for a familial Alzheimer's disease locus on chromosome 14. Science, 258, 668-671.

SChOENBerG, B. S., KoKInen, E. \& OKaZAKI, H. (1987) Alzheimer's disease and other dementing illnesses in a defined United States population. Incidence rates and clinical features. Annals of Neurology, 22, 724-729.

SELKOE, D. J., WATSON, D., HUNA, A. Y., et al (1993) Influence of the A4 C terminal sequence and of a FAD mutation of $\beta$ APP692 on the formation of amyloid $\beta$ peptide. Abstract for meeting of Society of Neuroscience, October 1993, Washington, DC.

St CIAIR, D. M. \& Whalley, L. J. (1983) Hypertension, multi-infarct dementia and Alzheimer's disease. British Journal of Psychiatry, 143, 274-276.

St George Hyslop, P. H., Tanzi, R. E., Polinsky, R. J., et al (1987) The genetic defect causing familial Alzheimer's disease maps on chromosome 21. Science, 235, 885-890.

, Haines, J. L., Rogaev, E., et al (1992) Genetic evidence for a novel familial Alzheimer's disease locus on chromosome 14. Nature Genetics, 2, 330-334.

Strittmater, W. J., Saunders, A. M., Schmechel, D., et al (1993) Apolipoprotein E: high affinity binding to $\beta \mathrm{A}$ amyloid and increased frequency of type 4 allele in familial Alzheimer's. Proceedings of the National Academy of Science, USA, 90, 1977-1981.

Van Broeckhoven, C., Backhovens, H., Cruts, M., et al (1992) Mapping of a gene predisposing to early-onset Alzheimer's disease to chromosome 14q24.3. Nature Genetics, 2, 335-339.

Van Duijn, C. M., Farrer, L. A., Cupples, L. A., et al (1993) Genetic transmission of Alzheimer's disease among families in a Dutch population based study. Journal of Medical Genetics, 30, 640-646.

Weitkamp, L. R., NeE, L., Keats, B., et al (1983) Alzheimer's disease: evidence of susceptibility loci on chromosome 6 and 14. American Journal of Human Genetics, 35, 443-453.

WISNIESKI, T. \& FRANGIONE, B. (1992) Apolipoprotein E: a pathological chaperone protein in patients with cerebral and systemic amyloid. Neuroscience Letters, 135, 235-238.

David St Clair, MPhil, DM, FRCS, MRCPsych, Wellcome Trust Senior Research Fellow, MRC Human Genetics Unit, Western General Hospital, Crewe Road, Edinburgh EH4 $2 X U$

(Received September 1993, accepted September 1993) 